\title{
2. DEFESAS DE TESES DO DEPARTAMENTO DE FILOSOFIA
}

\author{
FIGURA E ESCRITA NAS ARTES PLÁSTICAS \\ CONTEMPORÂNEAS
}

Doutoramento em Filosofia (Estética)

Prof. Wílcon Jóia Pereira

Faculdade de Filosofia, Ciências e Letras de Assis

Agôsto de 1973

Banca: Profs. Nilo Odália (Orientador), Décio Pignatari, Ubaldo Puppi, Haroldo de Campos e Fernando Manuel de Mendonça.

Trata-se de uma pesquisa sobre o emprego da linguagem nos trabalhos de artes visuais; mais precisamente, a respeito do uso de caracteres da escrita nos desenhos, quadros, esculturas, gravuras, colagens. Segundo o autor da tese, nas produções artísticas mais recentes ocorreria uma sistemática incorporação de materiais lingüísticos - grafemas de múltiplas dimensões, formas e naturezas, como por exemplo letras, sílabas, palavras, textos, ideogramas, pictogramas, hieróglifos, senhas, etc. . Isto não representaria um fenômeno isolado, de alcance restrito apenas aos domínios das belas-artes. Ao contrário, a espacialização ou figuração de unidades escriturais viria assumindo progressivamente o caráter de uma verdadeira prática significante, que já englobaria vários setores da vida contemporânea. Sobretudo porque a explicitação dos valores plásticos dos signos da linguagem escrita seria uma das técnicas mais essenciais e características da cultura de massa em fase de definição; com efeito, desvendar-se-ia aqui o próprio mecanismo de funcionamento de uma das linguagens típicas desta nova formação sócio-cultural: a logo-icônica, na designação de Roland Barthes.

O autor cuida de formular essa hipótese inicial de trabalho na primeira parte da exposição, a Introdução (p. 7-70) . Circunscreve, para facilitar a exemplificação, o período compreendido entre a Segunda Guerra e as vicissitudes da atual 
produção no domínio das artes plásticas. Demonstra, em seguida, como se daria efetivamente uma assimilação dos grafemas em todos os principais movimentos dos últimos decênios. Examina, para tanto, o abstracionismo (e, neste, sobretudo a execução de ideogramas assemânticos inspirados na caligrafia oriental), as tendências figurativas da pop-art e do nouveau réalisme, a hipergrafia dos letristas, os cartazes e definições na arte conceitual, etc. . Não marginalizou tampouco a produção brasileira: obras dos neoconcretos, desenhos de Mira Schendel, a figuração narrativa de Darci Penteado, inscrições líricas de Quiçak Júnior e outros.

Na segunda parte o autor ocupa-se da Ilustração (p. 71-147), onde analisa detalhadamente um elenco de 35 obras. Voluntariamente, buscou organizar um corpus bastante amplo e heteróclito, com pesquisas de variadas origens, soluções formais e merecimentos estéticos. Logo, sem nenhuma preocupação com os eventuais critérios antológicos, comenta pinturas de Indiana e Capogrossi, colagens de Paolozzi e Kolar, apropriações de Arman, esculturas de Gerchman, affiche descolado por Rotella, gravura de Bernik, environnement de Hamilton, néon de Chryssa, ideograma de Gotlieb, assinatura de Mathieu, tipografia de Reichert, intervenção no cotidiano por meio de panfletos distribuidos por Beuys, etc. .

Na terceira parte, designada Teoria (p. 148-244), lança a questão teórica mais decisiva: qual o estatuto e a função desses elementos, uma vez integrados aos demais recursos das artes visuais? Marca com ênfase a natureza sui generis, a especificidade e autonomia que assumem nesta original circunstância. Em oposição a Jean-François Lyotard, parıceu ao autor que já não se pode mais falar, no caso, em espaço de leitura e espaço de visão - distintos, embora enlaçados; pois a fusão de ambos provocaria o surgimento de uma única trama icônica, homogênea e complexa organização semiótica, "na qual se totalizam figura e texto na unidade orgânica de uma obra de arte", no dizer de Louis Marin. Para este novo objeto figurativo - para usar a expressão de Francastel - sugeriu a denominação de plástico-escritema. A alguns examinadores, porém, o têrmo pareceu impreciso e até mesmo rebarbativo. O autor confessou-se também insatisfeito e observou que, nas pesquisas futuras, gostaria de fixar outra noção, mais simples e menos ambígua.

Finalmente, na última parte, a Conclusão (p. 245-332) 
levando em conta um ensinamento de Gilles-Gaston Granger, o autor procurou inserir a referida prática "no seu contexto completo, e em particular nas condições sociais que lhe dão significado num mundo efetivamente vivido". Vale dizer: amplia-se a reflexão para que abarque um número maior possível de operações com a escrita. Incluir-se-ia assim, portanto, um minucioso panorama da situação vigente na cultura de massa: cartazes, histórias em quadrinhos, jornais, painéis, revistas ilustradas, folhetos, anúncios luminosos, cinema, televisão. Faz ainda o autor uma referência, para completar as linhas gerais do esbôço, às experiências de poesia visual e às narrativas onde os signos da escrita são manipulados a fim de exibir suas latentes possibilidades visuais - Mallarmé, Apollinaire, poemas concretos, Oswald de Andrade, Cortazar, Buzzati, Maurice Roche, etc.. Quase por unanimidade, os examinadores insistiram quanto à necessidade de um desdobramento da reflexão a partir deste ponto das investigações. Ou seja: tentar uma demonstração segura de que, na realidade, estaríamos em presença de uma linguagem que se torna aos poucos hegemônica, no âmbito de "um mundo efetivamente vivido"; o que está em vias de realização por parte do autor, que pesquisa no momento a iconização da linguagem nas revistas em quadrinhos. Seu próximo trabalho, consequentemente, propor-se-ia a uma abordagem direta da instigante problemática levantada pela indústria cultural.

COMISSÃO DE REDAÇÃO 
O INFLUXO DA BIBLIA NA VIDA E NO PENSAMENTO DE DOM MIGUEL DE UNAMUNO

Doutoramento em Ciências Humanas (História)

Prof. Jorge César Mota

Faculdade de Filosofia, Letras e Ciências Huamnas da Universidade de São Paulo

Abril de 1973

Banca: Profs. Eurípedes Simões de Paula (Orientador), Antônio Lázaro de Almeida Prado, João Cruz Costa, Theodoro Henrique Maurer Júnior, Júlio Garcia Morejón.

Segundo o autor da tese, nenhum leitor da volumosa obra do pensador e polígrafo espanhol Dom Miguel de Unamuno o basco que foi catedrático e reitor da Universidade de Salamanca, - deixará de notar o constante, abundante e inteligente (embora freqüentemente "heterodoxo") recurso à Bíblia Sagrada como fonte de inspiração poética ou estímulo para reflexão filosófica, teológica ou lingüística, ou ainda como apoio a argumentação moral ou simples ilustração didática. Muitos de seus críticos mencionaram, de passagem, o fato, sem nele se demorarem. Nada, até hoje, se tinha escrito especificamente sobre o assunto.

O autor da tese empreendeu a pesquisa na própria CasaMuseu de Dom Miguel de Unamuno, na Universidade de Salamanca, trabalhando sob a direção do Professor Manuel Garcia Blanco, antigo aluno de Dom Miguel e seu sucessor na cátedra .

A pesquisa foi dividida em duas fases. Na primeira, procurou-se verificar até onde mereceria atenção a presença da Bíblia na obra de Unamuno. Na segunda, que dependeria do sucesso da primeira, tratar-se-ia, em primeiro lugar, da busca de compreensão do fato no contexto histórico e social da Espanha do seu tempo (segunda metade do séc. XIX e primeira metade do séc. XX) . Em segundo lugar, seria necessário descobrir o significado dessa presença bíblica e seus reflexos na vida e no pensamento do filósofo.

A primeira fase da investigação levou ao seguinte resul- 
tado: numa obra de 16 volumes já publicados e muitos outros ainda inéditos, num total de cerca de 110 títulos, encontram-se mais de 170 títulos bíblicos (de livros, artigos, poemas, ensaios, etc.); pelo menos 77 referências ao Pai Nosso; cerca de 4.500 citações de textos bíblicos incluindo-se não só as que trazem a indicação do lugar nas Escrituras, como as que não o indicam, e também as passagens que embora não citadas de maneira alguma, transparecem do texto como sugestão, inspiração, analogia, reflexo ou alusão, mesmo quando citadas provavelmente involuntária ou inconscientemente. (Leve-se em conta que muito pouco do epistolário pôde ser consultado) .

Dados dessa grandeza e importância justificariam o prosseguimento do trabalho. Segundo o autor da tese, seria necessário levar em conta as circunstâncias adversas na Igreja Católica Romana de então, sobretudo na Espanha, que dificultava, ou proibia mesmo, a leitura da Bíblia em vernáculo, em particular em edições "protestantes" (o anátema de Pio IX contra as Sociedades Bíblicas "astutas e enganosas" é do ano em que Unamuno nasceu, 1864). Como explicar o fato de que desde muito cedo, teve o jovem estudante, talvez ainda em menino, o ensejo de se dedicar com tanto afinco à leitura e meditação das Sagradas Escrituras, a princípio na tradução de Reina e Valera, condenada pela Igreja, e mais tarde também no texto grego de Nestle do Novo Testamento (exemplar de que nunca se separava) e no hebráico de Kittel (ambos protestantes), a ponto de vir a ser proverbial e até objeto de comentários, nem sempre caridosos, o fato de ser Dom Miguel o escritor espanhol que mais lia a Bíblia Sagrada.

Teria ele encontrado o livro entre os que seu pai trouxera na pequena mas selecionada biblioteca adquirida no tempo em que esteve no México? Lá vivera provavelmente entre 1855 e 1859, ao tempo do presidente Juarez, o qual, segundo o testemunho do historiador Justo Sierra, declarara que fazia votos para que todos os índios se "protestantizassem" "para que aprendessem a ler". Te-lo-ia recebido das mãos do pastor evangélico que fixara residência em Bilbao no mesmo ano em que o menino Miguel completou 13 anos, e que viria a estabelecer relações com a família, pel omenos com seu irmão Felix? Também não se pode ignorar a ascendência huguenote de D. Miguel, nem tão pouco o seu particular interesse pelo estudo da língua de seu povo, o euskerra, cujo primeiro documento escrito foi exatamente o Novo Testa- 
mento, de Lizárraga, um huguenote. Também não é de se ignorar o fato de ter sido ele, em professor de espanhol de um grande número de ingleses, noruegueses e dinamarqueses, na sua maioria absoluta protestantes familiarizados com a Bíblia, livro que bem poderia ter servido de texto de leitura em virtude da facilidade de cotejo das diferentes línguas.

Enfim, os efeitos dessa leitura tão assídua das Escrituras ter-se-iam dado em diversos aspectos da sua carreira. Valendo-se de estatística, o autor demonstra que teria existido uma correlação entre os exemplos de maior inscidência de citações bíblicas na sua obra e os momentos mais emocionantes na sua vida: o doutoramento (1885), a cátedra em Salamanca (1891), a grande crise religiosa (1897), época de maiores pesquisas sobre questões religiosas (1911), destituição do cargo de reitor por Afonso XIII (1914), sob processo, acusado de injuriar o rei (1920), deportado por Primo de Rivera (1924), no exílio (1926-1930), morte da esposa (1934) .

Por outro lado, essa leitura teria deixado marcas profundas no seu pensamento, como aconteceu com Spinosa, Leibniz, Hegel Kierkegaard, Juan de la Cruz, Luiz de Leon, para só citar alguns dos que Unamuno mais freqüentava. Ter-se-ia refletid o no seu gosto pelo gênero epistolar, no seu estilo simples e ao mesmo tempo repleto de metáforas, parábolas, paradoxos. Na sua dialética Paulina. A vasta leitura de comentadores das Escrituras, sobretudo na obra de Kierkegaard e nos sermões dos maiores pregadores protestantes do seu tempo, no mundo anglo-saxão, ter-lhe-ia inspirado o admirável comentário exegético e homilético do $D$. Quixote. Os conceitos bíblicos de vocação (chamado de Deus) e de povo de Deus, tê-lo-iam levado a uma entrega total a Cristo, sem compromisso com qualquer das instituições eclesiásticas que trazem o seu nome, nem com qualquer modelo dogmático. Sua atitude e seus métodos te-lo-iam assim arrastado a uma posição "herética" que muitos dissabores lhe acarretou.

COMISSÃO DE REDAÇAO 


\section{IDEOLOGIA DO DESENVOLVIMENTO - ANÁLISE DE UMA INSTITUIÇÃO}

Doutoramento em Filosofia

Prof. Caio Navarro de Toledo

Faculdade de Filosofia, Ciências e Letras de Assis

Abril de 1974

Banca: Profs. Ubaldo Puppi (Orientador), Maria Sylvia Carvalho Franco, Francisco C. Weffort, Michel Debrun e Paulo Sérgio Moraes S. Pinheiro.

Partindo do pressuposto de que as ideologias não são simplesmente "sistemas conceituais", e que frequentemente as práticas ideológicas existem e se realizam no interior das formações sociais através de aparelhos e instituições materiais, procurou o autor examinar e verificar tal hipótese de trabalho mediante a análise de algumas das produções teórico-ideológicas formuladas por uma instituição criada e mantida pelo Estado brasileiro num passado bastante recente.

Se no caso de certas instituições pode-se, através da análise, desvendar o caráter ideológico de que se revestem suas atividades, programas e produções teóricas, na figura do Instituto Superior de Estudos Brasileiros (ISEB), segundo o autor, ter-se-ia a ideologia consagrada como marco definitivo da Instituição. Ao se buscar elucidar o significado, as direções, os pressupostos, os limites do "pensamento isebiano" basicamente aquele que acompanha o período chamado de "desenvolvimentismo" (Gov. Juscelino Kubitschek — 1956-1960) - a tese em questão procurou igualmente esclarecer em que medida a afirmação e a defesa (explícitas) - ou a "reabilitação" e promoção, como denominou o trabalho - da esfera ideológica se constituiriam num eloquente exemplo da "ideologização da ideologia".

Em dois momentos principais do trabalho procurou o autor qualificar essa "ideologização". Na I. ${ }^{a}$ Parte, quando demonstra que à prática ideológica (a rigor, a ideologia do desenvolvimento) são atribuidos os critérios de validação de 
toda a produção teórica; na III. a Parte a "ideologização" é esclarecida através do tratamento que se conferiu ao nacional-desenvolvimentismo, particularmente quando os isebianos pensam as relações existentes entre essa prática ideológica e as classes sociais no interior do capitalismo dependente brasileiro.

Os limites e contradições em que se esbarram o pensamento isebiano se explicariam em função dos pressupostos filosóficos e teóricos - insuficientemente dialéticos - de que se utilizaram seus autores (II Parte). Valendo-se de conceitos herdeiros do discurso antropológico - tal como, por exemplo, a alienação em sua versão existencial-humanista - e na ausência de instrumentos teóricos e metodológicos mais rigorosos que permitissem uma análise histórica e estrutural do capitalismo dependente brasileiro, não conseguiram os desenvolvimentistas do ISEB desatar as teias firmes e asfixiantes do discurso ideológico nas quais se enredou igualmente significativa parcela da intelectualidade brasileira nos anos 50 e 60 .

A tese em questão obedeceu ao seguinte plano:

Introdução - Acerca da Ideologia .

I. Parte: A ideologia como ante-factum.

Cap. 1: "Reabilitação" e promoção da ideologia.

Cap. 2: Teoria da ideologia em geral?

II. Parte - Pressupostos filosóficos das análises isebianas.

Cap. 1: A alienação como conceito-central.

Cap. 2: Influências filosóficas nos trabalhos isebianos.

III. Parte $-A$ Ideologia nacional-desenvolvimentista .

Cap. 1: A ideologia nacional-desenvolvimentista: as promessas da autonomia.

Cap. 2 : Desenvolvimento e dependência: as promessas não-realizadas.

Considerações finais.

Anexo (histórico do ISEB) .

Bibliografia . 
UNIVERSO, PROCESSO E ÉTICA NO “GRANDE SERTÃO: VEREDAS" - UMA ANALISE DO PENSAMENTO DE GUIMARÃES ROSA

Doutoramento em Filosofia (Etica)

Prof. Alvaro Martins Andrade

Faculdade de Filosofia, Ciências e Letras de Assis

Abril de 1974

Banca: Profs. Nilo Odália (Orientador), Dante Moreira Leite, João Alexandre Barbosa, Maria Aparecida Santilli e Wílcon Jóia Pereira.

Em trabalho intencionalmente interdisciplinar (Filosofia, Psicologia, Literatura), ocupa-se o autor da abordagem de aspectos específicos da obra rosiana que permitiriam estabelecer a estreita relação entre o ético e o psicológico no pensamento do autor mineiro, cuja temática é tratada mediante os quadros analíticos e instrumental conceitual da psicologia analítica de C. G. Jung. A partir da proposta inicial de que "o sertão é o inconsciente", verifica (particularmente no Grande Sertão: Veredas) a presença dos domínios do inconsciente pessoal (a memória, a narrativa), do eu pessoal (o narrador) e do inconsciente coletivo (o sertão a ser vencido). Da mesma forma e com o mesmo instrumental analítico foram identificados às personificações projetivas dos diferentes elementos estruturais e funções da totalidade psíquica: Diadorim-anima-sentimento, Hermógenes-sombra, Siruiz-intuição, Centro-ação-Medeiro Vaz-Joca Ramiro, Centro-Reflexão-Velho do Tebá-Quelemém, Otacília-o real.

Reconhecendo no autor o artista da linguagem, a tese aponta em que medida o Grande Sertão transcenderia a simples superação do regionalismo sertanista, constituindo-se na explicitação de um pensamento moral altamente elaborado. Com efeito, é mostrado em que medida a travessia do herói Riobaldo corresponde à trajetória de todos os mitos do herói, com sua moral implícita - a ética da transformação e da metamorfose. Valendo-se da noção junguiana de processo de transformação, a tese identifica na obra suas diferentes etapas e seu sentido moral. Retomando a consagrada tese (K. Krolow) de que a obra rosiana constituir-se-ia moral- 
mente em um engajamento do coração, a análise termina por revelar o engajamento também da vontade, o que a constituiria assim em um voluntarismo muito mais próximo às éticas européias e da ética subjacente ao pensamento do próprio C. G. Jung.

As várias etapas desta Análise do pensamento de Guimarães Rosa obedecem ao seguinte desenvolvimento:

Introdução

I - O universo. Teoria e método.

Introdução: Filosofia, Psicologia e Literatura.

1. A obra revista. Criação visionária.

2. O sonho e o mito: universo e linguagem.

3. O sertão é o inconsciente.

II - PROCESSO E ÉTICA

Introdução

1. O processo: conteúdo e objetivos, condições e características.

2. A dinâmica do processo.

3. A Ética.

Conclusões . 
A LEITURA DA OBRA DE LUCIEN FEBVRE E MARC BLOCH NOS ANNALES. INTRODUÇÃO A ANÁLISE DO CONHECIMENTO HISTÓRICO.

\author{
Doutorado em Filosofia
}

Prof. Ulysses Telles Guariba Netto

Faculdade de Filosofia, Ciências e Letras de Assis

Junho de 1974

Banca: Profs. Eurípedes Simões de Paula (Orientador), Eduardo d'Oliveira França, Maria Beatriz Nizza da Silva, José Ribeiro Júnior, Wílcon Jóia Pereira .

O trabalho desenvolve uma interpretação dos pressupostos teóricos constitutivos do pensamento histórico de Lucien Febvre e March Bloch, através da análise dos textos publicados nos "Annales" de 1929 a 1956.

Procurando recuperar, na obra de Febvre e Bloch, a "significação do programa de renovação que propõem para o campo do conhecimento histórico" (p. 6), o autor nos indica como, em seus textos, radicam os temas de um novo horizonte epistemológico que se constitui nas práticas teóricas das ciências do homem neste século. Para o autor, a interpretação desta revolução teórica se desenvolve em nossos dias e o trabalho de análise da obra de Lucien Febvre e Marc Bloch pretende contribuir para revelar a importância de suas teses críticas, quanto à possibilidadede de constituição do discurso histórico.

Propõe como objetivo secundário e polêmico introduzir, em nossa tradição de estudos históricos, uma via crítica de análise que conduza a um domínio cada vez mais adequado do processo de produção do conhecimento histórico. O diálogo com a obra de Febvre e Bloch, em seu processo de constituição, delineia, assim, um campo teórico à procura de sistematização, interpretação e desenvolvimento.

Entre a Introdução e as Considerações Finais, a exposição se articula em uma Primeira Parte: "A formação do pensamento histórico de Febvre e Bloch: O nascimento do projeto dos "Annales", e uma Segunda Parte: "Febvre e 
Bloch nos "Annales": A produção do conhecimento e a História".

Na primeira parte, procura o autor interpretar a emergência, nos textos de Febvre e Bloch, do tema da constituição do discurso histórico, gerado por diálogos com as concepções clássicas, que dominavam os trabalhos historiográficos franceses, e com novas perspectivas teóricas que se abrem nas ciências do homem, na primeira metade do século XX. A dupla polêmica, com a tradição e com as práticas teóricas inovadoras nas ciências do homem, conduz à constituição de um projeto de renovação dos estudos históricos, ao qual os "Annales d'histoire économique et sociale", darão forma e desenvolvimento, no espaço cultural francês.

Na segunda parte da tese, procura interpretar, através dos textos dos "Annales", a forma como os autores conduzem o projeto de renovação da pesquisa e da produção do conhecimento histórico. Determina o sentido do programa teórico dos autores, as realizações editoriais da revista, o estilo da polêmica desenvolvida, os contornos ideológicos de suas propostas e os pressupostos fundamentais de sua problemática. $\hat{E}$ interessante, notadamente, a interpretação das relações subjacentes, nos escritos dos autores, entre o esforço em dar positividade ao conhecimento histórico e a compreensão da história, como instância de conhecimento doadora de sentido à prática humana .

O resultado da interpretação desenvolvida, contribuiu para a compreensão dos limites da concepção de Febvre e Bloch do conhecimento histórico e permite, sobretudo, a releitura de seus textos sob a ótica das condições de produção do conhecimento, que, como diz o autor, "é a única leitura fundada de um discurso que se pretenda positivo" (p. 294) .

O autor procura destacar, em suas Considerações Finais, que o trabalho interpretativo desenvolvido "é fixação de uma problemática, isto é, de uma via através da qual outras investigações possam se ordenar. Faz fluir uma problemática de fundamentação da prática científica, a partir da qual o trabalho teórico refunde os sistemas que construiu, nos quais muitas vezes se aprisiona, para construir um espaço teórico novo que exige explicitação e trabalho criador...". 
Tendo fixado como sub-título da tese - "Introdução à análise do conhecimento histórico", procura indicar "estar latente em seu pensamento a problemática de um discurso possível sobre a prática teórica, sobre a ciência que se faz, como diria Marc Bloch". Entretanto, indica conviver muito mais com as dificuldades de tal empresa: "recusa de um discurso dogmático e preocupação de formular um discurso homogêneo à prática que procura interpretar". Daí porque, o exercício do diálogo com os textos de Lucien Febvre e Marc Bloch, assumem a forma de uma pesquisa dos seus fundamentos, dos seus núcleos temáticos centrais, das modalidades de integração e de sistematização de problemas, e de explicitação da compreensão dos autores da própria prática teórica que exercem. É exercício teórico de quem, insiste o autor, longe de ter determinado o espaço de sua problemática, procura constituí-la. "Como formular uma teoria da prática científica, em ação nas ciências do homem? Tal discurso comporta mil dificuldades. Neste campo somos todos aprendizes..." (p. 297) .

Deste ponto de vista, o trabalho se apresenta como um exercício de reflexão sobre as condições de interpretação da prática teórica no campo da ciência da história .

COMISSÃO DE REDAÇÃO 
O ESTATUTO EPISTEMOLÓGICO DAS "CIÊNCIAS INTERMEDIÁRIAS” SEGUNDO STO. TOMÁS DE AQUINO

\author{
Mestrado em Filosofia \\ Prof. Carlos Arthur Ribeiro do Nascimento \\ Instituto de Estudos Medievais da Universidade de \\ Montreal, Canadá
}

Agôsto de 1967

\title{
Banca: Profs. Jean Gagné e Benoît Lacroix
}

Tomás de Aquino fala explicitamente em algumas passagens de suas obras de um certo número de ciências intermediárias (scientiae mediae). A estes textos, segundo 0 autor da tese, deveriam ser acrescentados outros que tratam de problemas conexos. De todas estas passagens, as mais importantes seriam: In Boetii De Trinitate q. 5, a. 3, ad 6m; In Post. Analyticorum I, lect. 25, n. ${ }^{\circ}$ 1-6. In Physicorum II, lect. 3, n. ${ }^{\circ} 8-9$.

Os três textos supra citados forneceriam a quase-definição das ciências intermediárias que permanecerá substancialmente a mesma durante toda a obra de Tomás de Aquino: são denominadas tais, as ciências que aplicam os princípios abstratos da matemática (aritmética e geometria) à matéria sensível. As principais são a astronomia, a acústica e a ótica.

A aplicação dos princípios matemáticos à física se justificaria porque os "sujeitos" das duas ciências não seriam desprovidos de ligação entre si. O "sujeito" da física, embora não seja uma espécie propriamente dita do "sujeito" da matemática, manteria com êste relações que podem ser expressas em termos de "matéria" e "forma". Os domínios em que tal aplicação se dá, não se reduziriam portanto pura e simplesmente ao domínio da matemática pura (aritmética e geometria) mas constituiriam o campo próprio das ciências intermediárias subalternadas à matemática. Esta situação respectiva dos "sujeitos" das disciplinas matemáticas e das ciências intermediárias acarretaria consequências para o tipo de demonstração própria às primeiras e segundas. Os teoremas da matemática serão utilizados pelas ciências inter- 
mediárias para estabilizar demonstrativamente certas propriedades físicas constatadas anteriormente. Tratar-se-ia pois, de um saber de "que" (quia), visto as ciências intermediárias, enquanto tais, não demonstrarem os teoremas matemáticos de que se utilizam. Só a matemática pura atingiria à demonstração do "porque" (propter quid). No entanto, este recurso a princípios matemáticos de demonstração tornaria as ciências intermediárias mais próximas da matemática pura do que da física, embora de menor certeza que a matemática pura.

A maneira, portanto, como Tomás de Aquino aborda as ciências intermediárias, seria perfeitamente coerente nos seus diversos aspectos. O interesse desta abordagem é bem indicado por $\mathrm{O}$. Pedersen quando assinala na doutrina das ciências intermediárias um real progresso epistemológico. A noção moderna de física matemática era desconhecida da Idade média mas, com as ciências intermediárias, estaria se aproximando estreitamente dela. E não foi coisa de pouca monta caracterizá-las de modo preciso quando os exemplos disponíveis eram tão raros.

A tese do Prof. Carlos Arthur Ribeiro do Nascimento está em fase de publicação, pelo mesmo Instituto de Estudos Medievais (Montreal, Canadá) .

COMISSÃO DE REDAÇÃO 